www.jmscr.igmpublication.org

Impact Factor 5.244

Index Copernicus Value: 83.27

ISSN (e)-2347-176x ISSN (p) 2455-0450

crossref DOI: _http://dx.doi.org/10.18535/jmscr/v4i10.35

Journal Of Medical Science And Clinical Research

\title{
Bacteriological Profile and Antimicrobial Susceptibility of Blood Culture Isolates from Tertiary Care Hospital, Navi Mumbai
}

\author{
Authors \\ Jyoti P.Sonawane ${ }^{1}$, N.Kamath ${ }^{2}$, Keertana Shetty ${ }^{3}$, Rita Swaminathan ${ }^{4}$ \\ ${ }^{1}$ Assistant Professor, D Y Patil Medical College \& Hospital, Nerul, Navi Mumbai \\ ${ }^{2}$ Assistant Professor, D Y Patil Medical College \& Hospital, Nerul, Navi Mumbai \\ ${ }^{3}$ Assistant Professor, D Y Patil Medical College \& Hospital, Nerul, Navi Mumbai \\ ${ }^{4}$ Professor \& H.O.D., D Y Patil Medical College \& Hospital, Nerul, Navi Mumbai \\ Corresponding Author \\ Dr N.Kamath \\ Dept of Microbiology, D Y Patil Medical College \& Hospital, Nerul, Navi Mumbai \\ Email: nktallur@gmail.com, Mobile No. : 9769350033/9967587087
}

\begin{abstract}
Introduction: Blood stream infections (BSI) constitute a significant public health problem with increasing morbidity and mortality in hospitalized patients. Illnesses associated with blood-stream infections range from self-limiting infections to life threatening sepsis and require rapid and aggressive antimicrobial treatment. Again with the emergence of Multi-drug resistant organisms, there is increased risk of death in these patients.

Aim \& Objective: The present retrospective study was undertaken to know the profile of organisms causing bacteraemia with their antibiogram from clinically suspected cases of bacteraemia.

Materials and methods: Reports from the blood cultures submitted during the period of one year were analysed. 2994 blood culture samples were received to the microbiology laboratory. The bacterial isolates from positive cultures were identified by standard protocols and antimicrobial sensitivity patterns were determined by CLSI guidelines.

Results: Positive blood cultures were obtained in $10.29 \%$ (308/2994). Of 308 positive cultures, bacterial isolates were obtained in 286/ 308 (92.86\%) and 22/308 (7.14\%) were Candida spp. Of 286 bacterial isolates, Gramnegative bacteria accounted for 238 (83.22\%) cases and Gram-positive were 48(16.78\%) with predominance of Klebsiella spp. (22.38\%) followed by Pseudomonas spp. (20.98\%), Acinetobacter spp. (17.48\%) an E.coli $32(11.19 \%)$.

Among Enterobactericae, the high \% of ESBL production was seen in Klebsiella aeruginosa (55.66\%) and in E.coli (29.24\%), with highest sensitivity to Imipenem (97.66\%), Amikacin (60.16\%) and Piperacillin-tazobactum (52.34\%). All showed 100\% sensitivity to colistin. Among non-fermenters, Imipenem sensitivity was (91.82\%) followed by Piperacillin-tazobactum sensitivity (67.27\%) \& Amikacin sensitivity was (50\%). Colistin showed (94.55\%) sensitivity. Among Gram-positive isolates (16.78\%), Enterococcus spp. were (7.66\%) followed by Staphylococcus aureus (6.97\%). MRSA was seen in 10\% of S.aureus isolates. All Gram-positive isolates showed (100\%) sensitivity to Vancomycin and Linezolid.

Conclusion: The present study provides information on the most prevalent pathogens from blood cultures along with their sensitivity towards commonly used antimicrobials. The Majority of bacterial isolates were multidrug resistant. Thus providing useful guide to clinicians in initiating empiric therapy and will also help in formulation of antibiotic policy.

Keywords: Blood stream infections, ESBL, Multidrug resistant bacteria, Antibiotic policy.
\end{abstract}




\section{INTRODUCTION}

Bacteraemia is a state in which bacteria circulate through vascular system whereas Septicaemia is a life threatening condition when bacteria multiply at a rate that exceeds their removal by phagocytes. The symptoms are produced by microbial toxins and cytokines produced by inflammatory cells ${ }^{[1]}$. Microbial invasion of the blood stream can have serious consequences including shock, multiple organ failure, DIC and death. Thus frequently requiring admissions in ICU for appropriate management ${ }^{[2]}$. Blood stream infections range from self-limiting infections to life threatening sepsis that requires rapid and aggressive antimicrobial treatment ${ }^{[3] .}$ Bloodstream infections (BSI) are a major cause of morbidity and mortality worldwide. Approximately 200,000 cases of bacteraemia occur annually with mortality rates ranging from 20-50\% worldwide ${ }^{[2]}$. Many bacteria have been reported which cause bacteraemia with variation in distribution from place to place[4]. Organism isolated from blood culture vary according to geographical distribution, and development of multidrug resistant organism is of great concern, as they prolong hospital stay, increase cost of treatment and can be a cause of high mortality ${ }^{[5,6]}$. In recent years, there has been an increase in the incidence of bacteremia caused by the members of Enterobacteriaceae and other gram-negative bacilli. Sensitive bacterial strains are now being replaced by multi-drug resistant (MDR) strains of Klebsiella, Pseudomonas, Acinetobacter and Citrobacter species ${ }^{[7,8]}$. It is therefore necessary to document results obtained from analysis of blood culture for preparing the antibiotic policy for effective management of septicaemia. Timely administration of drugs in patients with septicaemia drastically reduces mortality rate ${ }^{[9]}$. Thus regular surveillance of blood stream etiology is important in monitoring the spectrum of bacterial pathogens and their sensitivity pattern and providing such data is not only necessary for the clinicians to be aware of the emerging resistant strains of pathogens that are a threat to the community but also provide platform to initiate effective empirical therapy ${ }^{[8,10]}$.
Therefore, this study was done to know the most frequent pathogens from septicaemia patients with their antibiotic susceptibility pattern thus providing useful guide to clinicians in initiating empiric therapy.

\section{MATERIALS AND METHODS}

A retrospective analysis was done in the Department of Microbiology Laboratory of Dr. D. Y. Patil Medical College and Hospital on blood samples received for culture over a period of one year from JUNE 2015 to JUNE 2016.

A total of 2994 blood culture samples from clinically suspected cases of septicaemia were received and processed. A Data on socioepidemiographic variables such as age, gender, blood culture results and their antibiotic susceptibility pattern were collected manually from laboratory record book for blood culture.

Blood samples were collected aseptically from patients for routine blood culture before taking any antibiotics. The venepuncture site was disinfected with $70 \%$ alcohol and $2 \%$ tincture of iodine before taking the sample.

From adults $10 \mathrm{ml}$, and children 3 to $5 \mathrm{ml}$ of blood was collected and immediately inoculated into Adult and Paediatric BACTEC blood culture vials respectively and incubated in BACTEC 9050 blood culture instrument (BectonDickenson, USA) at $37^{\circ} \mathrm{C}$.

All BACTEC positive samples were subjected to Gram staining followed by inoculation on $5 \%$ sheep blood agar, chocolate agar and MacConkey agar plates and were incubated at $37^{\circ} \mathrm{C}$ FOR 18 24 hours. Identification of isolates were done according to standard bacteriological technique and were identified based on the colony morphology, gram stain and biochemical tests such as Catalase, Coagulase, Bile esculine (BE), Optochin( OP) Bacitacin(BC) discs for Gram positive isolates and Oxidase, Indole, Citrate, Urease, Triple sugar iron tests for gram negative isolates with serological identification for Salmonella species ${ }^{[11,12,13]}$.

Antibiotic susceptibility testing was performed on Muller-Hinton agar by Kirby-Bauer Disk 


\section{JMSCR Vol||04||Issue||10||Page 13116-13124||October}

Diffusion method according to Clinical Laboratory Standard Institute (CLSI) guidelines ${ }^{14}$. For Gram positive bacteria, Ciprofloxacin (CIP) $(5 \mu \mathrm{g})$, Erythromycin (E) $(15 \mu \mathrm{g})$, Penicillin (P) (10U), Gentamycin (GM) $(10 \mu \mathrm{g})$, Vancomycin (VA) $(30 \mu \mathrm{g})$, Linezolid (LZ) $(30 \mu \mathrm{g})$, Oxacillin $(1 \mu \mathrm{g})$, Trimethoprim/Sulphamethoxazole (TMP) $(25 \mu \mathrm{g})$ were used.

For Gram negative bacteria, Ampicillin (AMP) $(10 \mu \mathrm{g})$, Gentamycin $(\mathrm{GM})(10 \mu \mathrm{g})$, Ciprofloxacin (CIP) $(5 \mu \mathrm{g})$, Cefotaxime $(30 \mu \mathrm{g})$, cefepime (30 $\mu \mathrm{g})$, Nalidixic acid(30 $\mu \mathrm{g})$, Ceftriaxone $(30 \mu \mathrm{g})$, Trimethoprim/Sulphamethoxazole (TMP) $(25 \mu \mathrm{g})$, Ceftazidime $(30 \mu \mathrm{g})$,Ceftazidime-Clavulanic acid (30/10 $\mu \mathrm{g})$, Tobramycin $(10 \mu \mathrm{g})$, Amikacin (30 $\mu \mathrm{g})$, Aztreonam $(30 \mu \mathrm{g})$, Colistin $(25 \mu \mathrm{g})$, Piperacillin-Tazobactum (100/10 $\mu \mathrm{g})$, Imipenum $(30 \mu \mathrm{g})$ were used which were procured from $\mathrm{Hi}-$ Media , Mumbai.

The susceptibility and resistance were interpreted according to Clinical Laboratory Standard Institute (CLSI) guidelines ${ }^{14}$. Escherichia coli (ATCC25922), Staphylococcus aureus (ATCC25923) and Pseudomonas aeruginosa (ATCC27853) were used as reference strains for culture and susceptibility testing.

\section{DATA ANALYSIS}

Data was analysed using Minitab 17.0 software. The z-test for proportion and Chi-square goodness of fit test was used to test significance. p-values of less than .05 were treated as significant

\section{RESULTS}

During the period from June 2015 to June 2016, 2994 blood samples from septicaemia suspected patients were received and processed routinely.

Out of 2994 blood cultures, 308 (10.29\%) were positive for culture growth.

TABLE 1. Age and Sex-wise distribution of positive blood cultures $(n=308)$

\begin{tabular}{|l|l|l|l|}
\hline AGE & MALES & FEMALES & TOTAL \\
\hline Infant (<1yr) & 36 & 18 & 54 \\
\hline Children (1-12yrs) & 32 & 16 & 48 \\
\hline Adolescent (13-18yrs) & 17 & 11 & 28 \\
\hline Adult (>18yrs) & 114 & 64 & 178 \\
\hline TOTAL & 199 & 109 & 308 \\
\hline
\end{tabular}

From 308 culture positive samples, 199 (64.61\%) were males and 109 (35.39\%) were Females with age ranging from 1 day to 90 years. Overall proportion of males was found to be significantly higher than the proportion of females $(\mathrm{p}<.001)$

TABLE 2: Ward-wise distribution of blood isolates. $(n=308)$

\begin{tabular}{|c|c|c|c|c|c|c|c|c|}
\hline Organisms & $\stackrel{\oslash}{己}$ & $\underset{\varrho}{\varrho}$ & 岕 & $\stackrel{己}{己}$ & $\sum_{\text {II }}^{3}$ & $\sum_{\Sigma}$ & 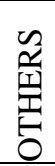 & $\begin{array}{l}\text { 杂 } \\
0 \\
0\end{array}$ \\
\hline Klebsiella Spp & 9 & 5 & 3 & 44 & - & 1 & 2 & 64 \\
\hline $\begin{array}{l}\text { Pseudomonas } \\
\text { aeruginosa }\end{array}$ & 10 & 3 & 2 & 34 & 5 & 4 & 2 & 60 \\
\hline $\begin{array}{l}\text { Acinetobacter } \\
\text { Spp }\end{array}$ & 7 & 6 & 2 & 32 & - & 1 & 2 & 50 \\
\hline E.coli & 4 & - & 1 & 23 & 3 & 1 & - & 32 \\
\hline S.typhi & - & 2 & 15 & 2 & & 2 & 1 & 22 \\
\hline Enterobact.sp & 4 & - & 2 & 3 & - & - & 1 & 10 \\
\hline S.aureus & 9 & 3 & - & 5 & 1 & 2 & - & 20 \\
\hline $\begin{array}{l}\text { Enterococcus } \\
\text { Spp }\end{array}$ & 7 & - & 4 & 9 & - & - & 2 & 22 \\
\hline $\begin{array}{l}\text { Streptococcus } \\
\text { spp }\end{array}$ & 4 & - & 1 & 1 & - & - & - & 06 \\
\hline Candida spp. & 6 & 1 & - & 13 & - & 1 & 1 & 22 \\
\hline TOTAL & 60 & 20 & 30 & 166 & 9 & 12 & 11 & 308 \\
\hline
\end{tabular}

p-values calculated using Chi-square goodness of fit test ( $\mathrm{p}$ $<.0001)$.

Out of 308 positive blood cultures, medical ICU showed maximum culture positivity $166(53.90 \%)$ followed by NICU \& PICU combined 81 $(26.30 \%)$.

Bacteremia was seen in $286(92.86 \%)$ of patients whereas fungaemia was seen in $22(7.14 \%)$ cases. All infections were monomicrobial.

Among 286 bacterial blood culture isolates, Gram negative and Gram positive bacteria constituted $238(83.22 \%)$ and 48(16.78\%), respectively.

Table 3: Distribution of bacterial isolates obtained from positive blood cultures. $(n=286)$

\begin{tabular}{|l|l|l|}
\hline Bacterial isolates & Number & Percentage (\%) \\
\hline Klebsiella pneumonia & 64 & $22.38 \%$ \\
\hline Pseudomonas spp. & 60 & $20.98 \%$ \\
\hline Acinetobacter spp. & 50 & $17.48 \%$ \\
\hline E.coli & 32 & $11.19 \%$ \\
\hline Salmonella typhi & 22 & $7.70 \%$ \\
\hline Enterococcus spp. & 22 & $7.70 \%$ \\
\hline S.aureus & 20 & $6.99 \%$ \\
\hline Enterobacter spp. & 10 & $3.50 \%$ \\
\hline Strep.spp & 06 & $2.10 \%$ \\
\hline TOTAL & 286 & $100 \%$ \\
\hline$P$-value & $<.001 * *$ \\
\hline p-value calculated using & Chi-square goodness of fit test
\end{tabular}


The predominant bacterial isolate from blood culture was Klebsiella pneumoniae $64(22.38 \%)$ followed by Pseudomonas aeruginosa 60 (20.98\%), Acinetobacter spp. 50 (17.48\%),E.coli 32 (11.19\%), Salmonella typhi 22(7.70\%),
Enterococcus spp. 22 (7.70\%), Staphylococcus aureus 20(6.99\%), Enterobacter spp. 10(3.50\%), Streptococcus spp. 6(2.10\%)

Table 4: Antibiotic sensitivity pattern of Gram-positive bacterial isolates in blood cultures ( $n=48)$

\begin{tabular}{|l|c|c|c|}
\hline Antibiotic & Enterococcus spp (n=22) & S.aureus (n=20) & $\begin{array}{c}\text { Streptococcus Spp } \\
(\mathrm{n}=06)\end{array}$ \\
\hline Penicillin & $0(0 \%)$ & $0(0)$ & $05(83.33 \%)$ \\
\hline Oxacillin & - & $18(90 \%)$ & - \\
\hline Erythromycin & $0(0)$ & $05(25 \%)$ & $05(83.33 \%)$ \\
\hline Gentamicin & $03(13.64 \%)$ & $10(50 \%)$ & $05(83.33 \%)$ \\
\hline Ciprofloxacin & $03(13.64 \%)$ & $10(50 \%)$ & $05(83.33 \%)$ \\
\hline Co-trimixazole & - & $06(30 \%)$ & - \\
\hline Vancomycin & $22(100 \%)$ & $20(100 \%)$ & $100 \%$ \\
\hline Linezolid & $22(100 \%)$ & $20(100 \%)$ & $100 \%$ \\
\hline p-value & $<.001 * *$ & $<.001 * *$ & $.0139 *$ \\
\hline
\end{tabular}

*: Sig. at 5\% level, **:Sig. at 1\% level, NS: Not significant,

p-values calculated using Chi-square goodness of fit test

All Gram - positive isolates showed 100\% sensitivity to Vancomycin and Linezolid.

MRSA was found in 2 isolates of S.aureus 2/20 $(10 \%)$.

The Gram-positive isolates showed high degree of resistance to Penicillin (89.58\%) followed by Erythromycin sensitivity in10 (20.83\%) and resistance in 38(79.17\%), Gentamicin sensitivity in $18(37.5 \%)$ and resistance in $30(62.50 \%)$, Ciprofloxacin sensitivity in $18(37.5 \%)$ and resistance in $30(62.50 \%)$, S.aureus showed Cotrimoxazole sensitivity in 6(30\%) and resistance in 14(70\%).

Table 5: Antibiotic sensitivity pattern of Gram-negative isolates in blood culture $(n=238)$

\begin{tabular}{|c|c|c|c|c|c|c|}
\hline Antibiotic & $\begin{array}{l}\text { Klebsiella } \\
\text { Spp(n=64) }\end{array}$ & $\begin{array}{c}\text { Pseudomonas } \\
\text { aeruginosa }(n=60)\end{array}$ & $\begin{array}{l}\text { Acinetobacter.spp } \\
(\mathrm{n}=50)\end{array}$ & $\begin{array}{l}\text { E.coli } \\
(\mathrm{n}=32)\end{array}$ & $\begin{array}{l}\text { Salmonella } \\
\quad(n=22)\end{array}$ & $\begin{array}{c}\text { Enterobacter } \\
\operatorname{Spp}(\mathrm{n}=10)\end{array}$ \\
\hline Amikacin & $31(48.44 \%)$ & $34(56.67 \%)$ & $21(42 \%)$ & $19(59.36 \%)$ & $22(100 \%)$ & $5(50 \%)$ \\
\hline Ampicillin & 0 & NT & 0 & $01(3.12 \%)$ & 0 & 0 \\
\hline Gentamicin & $24(37.50 \%)$ & $18(30 \%)$ & $16(32 \%)$ & $17(53.12 \%)$ & $22(100 \%)$ & $5(50 \%)$ \\
\hline Ciprofloxacin & $23(35.94 \%)$ & $32(53.33 \%)$ & $20(40 \%)$ & $4(12.5 \%)$ & $20(90.91 \%)$ & $4(40 \%)$ \\
\hline Ceftazidime & $5(7.81 \%)$ & $29(48.33 \%)$ & $11(22 \%)$ & $1(3.12 \%)$ & - & $4(40 \%)$ \\
\hline $\begin{array}{l}\text { Ceftazidime+Clavulanic } \\
\text { acid }\end{array}$ & $5(7.81 \%)$ & NT & $11(22 \%)$ & $1(3.12 \%)$ & - & $4(40 \%)$ \\
\hline Cefotaxime & $5(7.81 \%)$ & $13(21.67 \%)$ & $11(22 \%)$ & $1(3.12 \%)$ & $20(90.91 \%)$ & $4(40 \%)$ \\
\hline Ceftriaxone & $5(7.81 \%)$ & $13(21.67 \%)$ & $11(22 \%)$ & $1(3.12 \%)$ & $20(90.91 \%)$ & $4(40 \%)$ \\
\hline Piperacillin -Tazobactam & $25(39.06 \%)$ & $47(78.33 \%)$ & $27(54 \%)$ & $14(43.75 \%)$ & - & $6(60 \%)$ \\
\hline Imipenem & $61(95.31 \%)$ & $57(95 \%)$ & $44(88 \%)$ & $32(100 \%)$ & $22(100 \%)$ & $10(100 \%)$ \\
\hline Colistin & $64(100 \%)$ & $58(96.67 \%)$ & $46(92 \%)$ & $32(100 \%)$ & $22(100 \%)$ & $10(100 \%)$ \\
\hline CoT & $11(17.19 \%)$ & NT & $19(38 \%)$ & $4(12.5 \%)$ & $22(100 \%)$ & $4(40 \%)$ \\
\hline Nalidixic acid & NT & NT & NT & NT & $20(90.91 \%)$ & NT \\
\hline Aztreonam & NT & $2(3.33 \%)$ & NT & NT & NT & NT \\
\hline Tobramycin & NT & $30(50 \%)$ & NT & NT & NT & NT \\
\hline Cefepime & NT & $21(35 \%)$ & NT & NT & NT & NT \\
\hline p-vaues & $<.001 * *$ & $<.001 * *$ & $<.001 * *$ & $<.001 * *$ & $\mathrm{P}=.02 *$ & $\mathrm{P}=.127, \mathrm{NS}$ \\
\hline
\end{tabular}

*: Sig. at 5\% level, **:Sig. at 1\% level, NS: Not significant, NT- Not Tested.

p-values calculated using Chi-square goodness of fit test 
Among Enterobactericae (128), 98 (76.56\%) isolates were resistant to 3rd. generation Cephalosporins. \% of ESBL production (106), in E.coli is (29.24\%), Klebsiella aeruginosa $(55.66 \%)$ and Enterobacter spp. (5.66\%). Imipenem sensitivity was seen in $125(97.66 \%)$ and resistance in 3(2.34\%). All showed 100\% sensitivity to colistin. Amikacin sensitivity in $77(60.16 \%)$ and resistance in 51(39.84\%). Piperacillin-tazobactum sensitivity in 67(52.34\%) and resistance in $61(47.66 \%)$. Ciprofloxacin sensitivity seen in $51(39.84 \%)$ resistance in 77 $(60.16 \%)$. Gentamicin sensitivity in $68(53.13 \%)$ and resistance in 60(46.87\%).

Among non-fermenters (110), Imipenem sensitivity was seen in 101(91.82\%) and resistance seen in $9(8.18 \%)$. Colistin sensitivity was seen in 104(94.55\%) and resistance was seen in 6(5.45\%).Amikacin sensitivity in 55(50\%) and resistance in $55(50 \%)$. PIT sensitivity in $74(67.27 \%)$ and resistance in $36(32.73 \%)$. Ampicillin resistant was seen in 237 (99.58\%) of Gram-negative isolates. S.typhi showed $100 \%$ resistance to Ampicillin and $90.91 \%$ sensitive to Ciprofloxacin.

\section{DISCUSSION}

The present study provides information on the distribution of bacterial isolates causing bloodstream infections along with their antibiotic susceptibility pattern that plays a crucial role in effective management of septicaemic cases.

In our study, the blood culture positivity rate in clinically suspected septicaemia cases was $10.29 \%$, which was approximately similar to the studies by Manjula Et al 2005 ${ }^{[15]}$ showed 9.94\% by Usha and Pushpa $2007^{[16]}$ showed $10 \%$ and Mehta Et al 2005 ${ }^{[17]}$ showed $9.94 \%$ positivity rate and $11.2 \%$ Shalini s et al $2010^{[18]}$ and $10.8 \%$ from Iran,Hamed Ghadhiri et al 2012 $2^{[19]}$.

In contrast to the above reports, the studies done in India and other countries have reported high frequency of positive blood culture ranging from 18 to $45 \%{ }^{[20-27]}$.

Such differences in prevalence of BSI across countries could be due to the difference in blood culture system, the study design, geographical location, nature of patient population, epidemiological difference of the etiological agents, and differences in the infection control policies between nations ${ }^{[6,25,27]}$. Bacteraemia was seen in $286(92.86 \%)$ of patients whereas fungaemia was seen in $22(7.14 \%)$ cases.

From total septicaemia cases, 199 (64.61\%) were males and 109 (35.39\%) were Females. Pathogen isolation rate was found to be high in medical ICUs (53.90\%) followed by NICU and PICU (26.30\%).

In our study, Gram negative and Gram positive bacteria constituted $83.22 \%$ and $16.78 \%$ respectively. Similar to the present study, in most of the studies, gram negative bacilli have taken over the gram-positive organisms, especially in hospital settings. This finding was in accordance with other studies $[7,8,17,23,28,29.30 .31,32,33]$.

In our study, the predominant isolates were Klebsiella pneumoniae 64 (22.38\%) followed by Pseudomonas aeruginosa 60(20.98\%), Acinetobacter spp. 50 (17.48\%), E.coli 32 (11.19\%), which was in accordance with other studies ${ }^{[7,8,23]}$. The high occurrence of non-lactosefermenters especially Pseudomonas spp. \& Acinetobacter spp., which has emerged as important nosocomial pathogens, is of concern; both of these bacteria are associated with a high degree of resistance to antibiotics and are associated with high morbidity and mortality ${ }^{[7,8,28, \text { and } 32]}$.

In our study, S.typhi was isolated in $7.70 \%$ of total cases which was quiet comparable to the findings by Wasihun, Wlekidan $2015^{[25]}$ who reported about 5.6\% S.typhi. But the other studies reported an increasing incidence of Salmonella species between $12 \%$ and $15 \%{ }^{[7,17,32]}$.

In our study, we found all cases of bacteremia with single microorganism similar to other studies $[23,27,35]$.

Surprisingly, in our study Gram-positive isolation from BSI was low $16.78 \%$. Among the Grampositive isolates from total bacteremic cases, the most predominant isolate was Enterococcus spp. $7.70 \%$ followed by S.aureus $6.99 \%$ whereas studies by Mathur et al 2014 ${ }^{[28]}$ reported $9 \%$ and 
Vanitha Et al 2012 $2^{[7]}$ who isolated $8.7 \%$ Enterococcus spp. But their predominant Grampositive isolate was S.aureus. Such low isolation of Gram-positive pathogens suggest an increasing emergence of Gram-negative isolates with Multidrug resistance and ESBL production, so a strict antibiotic policy should be implemented with emphasis on local susceptibility findings ${ }^{[34]}$.

MRSA was found in 2 isolates of S.aureus 2/20 (10\%) All Gram - positive isolates showed 100\% sensitivity to Vancomycin and Linezolid. With increasing resistance to Penicillin $(89.58 \%)$ Gentamicin (62.50\%), Ciprofloxacin (62.50\%) and Erythromycin $(79.17 \%)$.

In the present study $55.66 \%$ of Klebsiella pneumoniae and $29.24 \%$ of E.coli \& $5.66 \%$ of Enterobacter spp. were ESBL producers which was higher than the other studies ${ }^{[6,21]}$ but such high level of ESBL production was also seen in studies by other authors ${ }^{[23,34]}$.

Among Enterobactericeae, Imipenem sensitivity was seen in $97.66 \%$ and resistance in $2.34 \%$ which was consistent with the other study ${ }^{[34]}$. Above observation on possible emergence of Carbapenem-resistant Enterobactereciae point towards the possible irrational use of carbapenems occurs $^{[36]}$. All showed $100 \%$ sensitivity to colistin. All Enterobactereciae showed better activity to Amikacin 60.16\%, Piperacillin-Tazobactum combination $52.34 \%$ and Gentamicin $53.13 \%$. Among non-fermenters, Imipenem sensitivity was seen in $91.82 \%$ and resistance in $8.18 \%$. Colistin sensitivity $94.55 \%$ and showed better activities to Piperacillin-Tazobactum $67.27 \%$ followed by Amikacin 50\%.These results were comparable to other studies ${ }^{[32,37]}$

S. pneumoniae were isolated. Given this steadily growing danger of MDR and ESBL-producing isolates in South Kivu, as underlined by our findings, a strict antibiotic policy should be implemented urgently in the province with an emphasis on local susceptibility findings.

Another important issue in the province is the lack of regulation regarding prescription of antibiotics, which are widely used, even for minor illnesses such as rhinitis. Whereas no study has assessed this phenomenon, it is worth noting that a recent study documented a high level of irrational prescription of antibiotics by healthcare profession associated with a steady increase of antimicrobial drug resistance.

The study identified Gram negative bacteria as the predominant organisms causing blood stream infections and most of them were found to be multi-drug resistant. Carbapenems, PiperacillinTazobactum combination and amikacin were found to be most effective for Gram-negative isolates whereas Vancomycin and Linezolid were found to be most effective for Gram-positive isolates.. The increase in the prevalence of Multidrug-resistant bacteria emphasize the immediate need for rational use of antibiotics, formulation of antibiotic policy, and implementation of infection control practices for the effective management and prevention of drug resistance.

Gram-positive bacteria did not play an important role in BSI when compared with other studies in associated with a steady increase of antimicrobial drug resistance

\section{CONCLUSION}

Bacteraemia is an independent risk factor of morbidity and mortality in cases of septicaemia. With the emergence of multi resistant bacteria in many regions worldwide, leaving limited options for treatment. Thus timely detection and knowledge of most likely pathogens causing BSI along with their antibiotic susceptibility pattern will help the clinicians in choosing appropriate antimicrobials for treatment which will reduce the major burden of BSIs in critically ill patients and will also minimize the further emergence of resistance. Therefore, there should be an intensive surveillance, antibiotic policy formulations and preventive efforts for the effective management and prevention of drug resistance.

\section{REFERENCES}

1. Elmer Koneman, Washington C. Winn, jr., Stephen allen,William janda et al. Koneman s color atlas and textbook of diagnostic microbiology, 6th edition. Page no.97. 
2. P.A.Fuselier, L.S.Garcia, G.W. Procop et al., "Blood stream infections," in Bailey and Scott"" s Diagnostic microbiology, A.F. Betty, F.S. Daniel and S.W.Alice, Eds., pp. 865-883, Mosby,2002.

3. Young LS. Sepsis syndrome. In: Mandell GL, Bennet JE, Dolin R,editors. Principle and Practice of Infectious Diseases. Elsevier:Churchill Livingstone; 1995. p. 690-705.

4. Daniel RK,Scott AF,James MB,Sanjay S (2006).Brief Report on Incidence, etiology, risk factors and outcome of Hospital acquired fever. J Gen Intern Med 21: 1184-1187.

5. Tziamabos A O, Kasper D L (2005) Principle and Practice of Infectioous Diseases.Frank Polizano J,26 : 2810-2816.

6. Kalpesh Gohel, Amit Jojera, Shailesh Soni, Sishir Gang,Ravindra Sabnis, and Mahesh Desai Bacteriological Profile and Drug Resistance Patterns of Blood Culture Isolates in a Tertiary Care Nephrourology Teaching Institute BioMed Research International, Volume 2014, Article ID 153747, 5 pages, 2014, doi: 10.1155/2014/153747.

7. Vanitha RN, Kannan G, Venkata NM, Vishwakanth D, Nagesh VR,Yogitha M, et al. A retrospective study on blood stream infectionsand antibiotic susceptibility patterns in a tertiary care teachinghospital. Int J Pharm Pharm Sci 2012; 4:543-8.

8. Shilpi Gupta, Bineeta Kashyap. Bacteriological profile and antibiogram of blood culture isolates from a tertiary care hospital of North India. Tropical J. Medical research.Vol.19.Issue.2.Jul-Dec 2016, 94-99.

9. Warren DK, Zack JE, Elward AM, Cox MJ, Fraser VJ. Nosocomial primary bloodstream infections in intensive care unit patients in a nonteaching community medical center: A 21-month prospective study. Clin Infect Dis 2001; 33:1329-35.
10. Karunakaran R, Raja NS, Ng KP, Navratnam P. Etiology of blood culture isolates among patients in a multidisciplinary teaching hospital in Kuala Lumpur. J Microbiol Immunol Infect 2007; 40; 432-437.

11. Cruickshank K, Duguid JP, Marmion BP. Test for sensitivity to microbial agents. In: Medical Microbiology. Chuchill Livingstone, 1980; 190-209.

12. Cheesbrough, M. District laboratory practice in tropical countries.2. Vol.2. Cambridge, UK : Cambridge University press;2000.p.124-5.

13. Murray, B; Pfaller, T.Manual of Clinical Miceobiology.6. American Society of Microbiology Press; Washington DC: 1999.

14. Clinical and Laboratory Standards Institute (CLSI). 20 th Informational Supplement. Wayne, PA: CLSI; 2012. Performance Standards for Antimicrobial Susceptibility Testing. CLSI document M100-S20.

15. Manjula M, Pyria D, Varsha G: Antimicrobial susceptibility pattern of blood isolates from a teaching Hospital in north India. Japan J Infec Dis 2005, 58:174 176.

16. Usha A, Pushpa D (2007) Bacterial profile of bloodstream infections and antibiotic resistance pattern of isolates. J K Sci 9(4):186-190.

17. Mehta M, Dutta P, Gupta V. Antimicrobial susceptibility patternof blood isolates from a teaching hospital in north India.Jpn.J. Infect Dis 2005; 58:174-6.

18. Shalini S, Kranthi K, Gopalkrishna BK. The microbiological profile of nosocomial infections in the intensive care unit. J Clin Diagn Res 2010; 4: 3109-12.

19. Hamed Ghadiri,1 Hamid Vaez,2 Samira Khosravi,3 and Ebrahim Soleymani3.The Antibiotic Resistance Profiles of Bacterial Strains Isolated from Patientswith Hospital-Acquired Bloodstream and Urinary Tract Infections. Critical Care 
Research and Practice Volume 2012, Article ID 890797.

20. Khanal B, Harish BN, Sethuraman KR, Srinivasan S. Infective endocarditis: Report of a prospective study in an Indian hospital.Trop Doct 2002; 32:83-5

21. Arora U, Devi P. Bacterial profile of blood stream infections and antibiotic resistance pattern of isolates. J K Sci 2007; 9:186-90.

22. Garg A, Anupurba S, Garg J, Goyal RK, Sen MR. Bacteriologicalprofile and antimicrobial resistance of blood culture isolatesfrom a university hospital. J Indian Acad Clin Med 2007; 8:139-43.

23. Nidhi Pal and Ramamurthy Sujatha, Microbiological Profile and Antimicrobial Resistant Pattern of Blood Culture Isolates, Among Septicaemia Suspected Patients. National Journal of Laboratory Medicine. 2016 Jan, Vol 5(1): 17-21.

24. Ali J, Kebede Y. Frequency of isolation and antimicrobial susceptibility pattern of bacterial isolates from blood culture, Gondar University teaching hospital, Northwest Ethiopia. Ethiop Med J. 2008; 46(2):155-61.

25. Araya G.Wasihun, Letemichael N. Wlekidan, Senay A. Gebremariam, Tsehaye A. Dejene A. L. Welderrufael, T. D. Haile and saravanan Muthupandian.Bacteriological profile and antimicrobnial patterns of blood culture isolates among febrile patients in Mekelle Hospital, Northern Ethiopia. SpringerPlus (2015) $4: 314$.

26. Philip $\mathrm{CH}$, Charles OO, Usman NAI, Ousman S, Samual A, Naomi S et al (2007) Bacteremia in patients admitted to an urban hospital in west Africa.BMC Infect Dis 7(2): 1-8.

27. Dagnew M, Yismaw $G$ et al. Bacterial profile and antimicrobial susceptibility pattern in septicemia suspected patients attending Gondar University Hospital,
Northwest Ethiopia. BMC Res Notes. 2013; 6: 283.

28. Mathur P, Varghese P, Tak V, Gunjiyal J,Lalwani S, Kumar S, Misra MC. Epidemiology ofblood stream infections at a level-1 trauma care center of India. J Lab Physicians 2014; 6:22-7.

29. Sharma PP, Halder D, Dutta AK, Dutta R,Bhatnagar S, Bali A et al. Bacteriological profile of neonatal septicemia. Indian Pediatr J 1987; 24:1011-7.

30. I. Roy, A. Jain, M. Kumar, and S. K. Agarwal, "Bacteriology of neonatal septicemia in a tertiary care hospital of Northern India," Indian Journal of Medical Microbiology, vol. 20, pp. 156-159, 2002.

31. Devi V, Sahoo B, Damrolien S, Praveen S, Lungran P, Devi M.A study on the bacterial profile of bloodstream infections inRims Hospital. J Dent Med Sci 2015;14:18-23.12.

32. Chhina D, Gupta V. Bacteriological profile and antimicrobialsusceptibility pattern of Blood isolates from a tertiary carehospital in North India. IJPRBS 2013;2:24-35.

33. Asrat D, Amanuel YW. Prevalence and antibiotic susceptibility [30]pattern of bacterial isolates from blood culture in Tikur Anbassa Hospital, Addis Ababa, Ethiopia. Ethiop Med J. 2001; 39(2):97104.

34. Leonid M Irenge, Landry Kabego, Faustin B Kinunus, Rapheal B Chirimwami. Antimicrobial resistance of bacteria isolated from patients with bloosstream infections at a tertiary care hospital in the Democratic Republic of the Congo. SAMJ.Sept.2015, Vol.105, No.9; 752-755.

35. Ghanshyam DK, Ramachandram VC, Piyush G. Bacteriological analysis of blood culture. Malaysian J Microbio. 2008; 4(Suppl 2):51-61. 30

36. Poirel I,Revathi G, Bernabeu S, et al.Detection of NDM I producing Kleibsiella pneumonia in Kenya. 
Antimicrob Agents Chemother 2011;55 (2):934-936.

37. Datta S, Wattal C, Goel N, J.K. Raveendran, Prasad K.J.(2012) "A ten year analysis of Multi-drug resistant Blood stream infections caused by E.coli \& Klebsiella pneumonia in a tertiary care hospital," Indian Journal of Medical Reasearch, 135 (6)907-12. 